\title{
THE LIPOLYTIC ACTIVITY OF MICROCOCCACEAE FROM HUMAN AND ANIMAL SOURCES
}

\author{
V. G. Alder*, W. A. Gillespie*, R. G. Mitchell $\dagger$ AND \\ KIRSTEN ROSENDAL $\ddagger$ \\ * Department of Pathology, United Bristol Hospitals, Bristol, BS2 $8 H W, \dagger$ Department of \\ Pathology, The Churchill Hospital, Headington, Oxford, England, and $\ddagger$ Statens \\ Seruminstitut, DK 2300 Copenhagen S., Denmark
}

THE Micrococcaceae have lipolytic activity that can be recognised by the precipitation of salts of fatty acids around colonies on nutrient agar containing lipid substrates. Some strains hydrolyse only compounds with short-chain fatty acids, and others hydrolyse compounds with longer chains as well as short chains (Gillespie and Alder, 1952; Baird-Parker, 1963, 1965; Stewart, 1965; Patterson, 1966; Tirunarayanan and Lundbeck, 1968). Gillespie and Alder found that many coagulase-positive staphylococci produced opacity in egg-yolk glucose broth, whereas coagulase-negative strains did not have this property. The egg-yolk reaction is caused by a lipase (Gillespie and Alder; Shah and Wilson, 1963; Scrimgeour, Keane and Alder, 1967; Tirunarayanan and Lundbeck), and is inhibited by commercial staphylococcal antitoxic serum. Egg-yolk-positive strains hydrolyse Tween 80 (polyoxyethylene sorbitan monooleate) by means of a lipase (Sierra, 1957) but whether the same or a different lipase is responsible for this reaction and for the reaction in egg-yolk broth is not known. Alder, Gillespie and Herdan (1953) found that strains of Staphylococcus aureus from human sources gave a positive egg-yolk reaction more often than did strains from animal sources, but a comprehensive investigation of the lipolytic activities of the Micrococcaceae in general has not been reported.

In this paper, we describe the action of Micrococcaceae from human and from many different animal sources on several lipid substrates, and the effect of rabbit antisera prepared against representative strains on lipolysis.

\section{MATERIALS AND METHODS \\ Sources of the bacteria}

The 413 strains of coagulase-positive staphylococci ( $S$. aureus) that we examined comprised 368 from human sources, including pathological material and the normal skin and nose of hospital patients and laboratory staff in Bristol and Denmark, 36 from lesions in cattle and pigs, six from the fur of farm and laboratory animals and three from bacon. The 677 strains of catalase-positive, coagulase-negative cocci were from the following sources: 414 from human pathological material and from the skin of patients and laboratory staff in hospitals in Bristol and Denmark; 82 from the skin and hair of horses, cattle, sheep, hamsters and rats at an animal farm belonging to the Statens Seruminstitut, Copenhagen; 158 from various animals (zebras, antelopes, gazelles, buffaloes, bison, camels, okapi, yaks, deer, 
goats, Shetland ponies, a surikate and single specimens of two species of mongoose) at the Zoological Gardens, Copenhagen; and 23 from bacon.

Coagulase production was determined by Gillespie's (1943) method. Coagulase-positive cultures were phage typed by the method of Blair and Williams (1961) with the International Basic Set of phages (Report, 1967) and with a new phage no. 6557 (Bülow, 1968), now given the official number 93 (Report, 1971). Coagulase-negative cocci were classified as staphylococci and micrococci according to the system of Baird-Parker (1963).

\section{Sampling techniques}

Bacteria from human skin and from the skin and hair of animals were collected by the technique of Thomas (1961) on " Presson" self-adhesive labels (Norprint Ltd, Horncastle Road, Boston, Lincs). These were placed for about 1 min. on blood agar plates, which were then incubated at $37^{\circ} \mathrm{C}$ for $24 \mathrm{hr}$. It was not possible to collect organisms directly from the skin of a few timid animals, but organisms were obtained by swabbing greasy areas on the woodwork against which the animals had rubbed. Representative colonies were subcultured to nutrient agar slopes for storage.

\section{Assessment of lipolytic activity}

The egg-yolk reaction was performed in egg-yolk glucose broth (Gillespie and Alder). Hydrolysis of Tween compounds was assessed on Sierra's agar medium containing one of the following substrates: Tween 20 (polyoxyethylene sorbitan monolaurate), Tween 80 (polyoxyethylene sorbitan monooleate) and Tween 85 (polyoxyethylene sorbitan trioleate). The Tween-agar medium was seeded from overnight cultures on nutrient agar by means of a platinum loop, so as to produce macrocolonies at least $6 \mathrm{~mm}$ in diameter. The plates were incubated aerobically at $37^{\circ} \mathrm{C}$ for 3 days, and the width of the zones of precipitation around the colonies was measured within $24 \mathrm{hr}$ of the removal of the plate from the incubator. Strains with visible precipitation around the colony were regarded as positive; those with zones less than $2 \mathrm{~mm}$ in width were recorded as weakly positive and those with zones $2 \mathrm{~mm}$ or more in width as strongly positive.

\section{Preparation of antisera}

The antigenic activity of different lipases was studied by immunising rabbits with five strains that differed in their patterns of lipolytic activity (table I). Overnight cultures on nutrient agar were harvested in physiological saline and shaken for $15 \mathrm{~min}$. with glass beads. Three rabbits were immunised with each organism. The first six injections were of a suspension killed by heating at $56^{\circ} \mathrm{C}$ for $18 \mathrm{hr}$ and standardised to contain $2 \times 10^{8}$ organisms per $\mathrm{ml} ; 0.2 \mathrm{ml}$ of this suspension was injected intravenously each day for 3 days, and, after a rest of 3 days, $0.5 \mathrm{ml}$ was injected daily for 3 more days. Then, 7 days later, $0.25 \mathrm{ml}$ of living suspension $\left(10^{8}\right.$ per $\left.\mathrm{ml}\right)$ was injected, followed 3 days later by two more daily injections of the same volume, and then by three daily injections of $0.5 \mathrm{ml}$, of living suspension. Animals that became ill were given four daily injections of a mixture of benzylpenicillin 60,000 units, procaine penicillin 30,000 units, benzathine penicillin 60,000 units and dihydrostreptomycin $60 \mathrm{mg}$. All the staphylococci used in these experiments were sensitive to streptomycin and all but one to penicillin. The animals were bled before immunisation and 17 days after the end of the course.

\section{Tests for antibodies}

Antibody against the egg-yolk lipase in rabbit sera and in a commercial staphylococcal antiserum (Wellcome Reagents) was titrated in egg-yolk glucose broth (Gillespie and Alder). Antibody against lipolytic activity on Tween media and on 5 per cent. egg-yolk agar was detected qualitatively by streaking the cultures on to plates, half the surface of which had been smeared with serum. Antibody to $\alpha$-lysin was estimated by the method of Parish, 
O'Meara and Clark (1934). Each serum was examined by Ouchterlony's (1953) doublediffusion method for precipitation against an extract of the immunising strain that had been prepared by disintegration in a press (Raper and Hyatt, 1963).

TABLE I

Properties of the strains used to immunise rabbits

\begin{tabular}{|c|c|c|c|c|c|c|c|}
\hline \multirow{2}{*}{$\begin{array}{l}\text { Strain } \\
\text { number }\end{array}$} & \multirow{2}{*}{$\begin{array}{l}\text { Phage-typing } \\
\text { pattern* }\end{array}$} & \multirow{2}{*}{$\begin{array}{l}\text { Coagulase } \\
\text { production }\end{array}$} & \multirow{2}{*}{$\begin{array}{c}\alpha \text {-Lysin } \\
\text { production }\end{array}$} & \multirow{2}{*}{$\begin{array}{l}\text { Egg-yolk } \\
\text { reaction }\end{array}$} & \multicolumn{3}{|c|}{$\begin{array}{l}\text { Lipase production } \\
\text { on Tween }\end{array}$} \\
\hline & & & & & 20 & 80 & 85 \\
\hline 1 & $\begin{array}{c}52 / 52 \mathrm{~A} / 80 /+ \\
(29 / 52 / 52 \mathrm{~A} / 80)\end{array}$ & + & + & + & + & + & + \\
\hline 2 & $(29 / 52+)$ & + & + & - & + & + & + \\
\hline 3 & $(52 / 79)$ & + & + & - & + & - & - \\
\hline 4 & (Not typable) & - & - & - & + & + & + \\
\hline 5 & (Not typable) & - & - & - & + & - & w \\
\hline
\end{tabular}

$+=$ Positive reaction, $\mathrm{w}=$ weakly positive reaction, $-=$ negative reaction.

* At RTD (and at RTD $\times 1000$ ).

TABLE II

Tween reaction, egg-yolk reaction and phage-typing patterns of Staphylococcus aureus cultures

\begin{tabular}{|c|c|c|c|c|c|c|c|}
\hline \multirow[b]{3}{*}{$\begin{array}{l}\text { Phage } \\
\text { group }\end{array}$} & \multirow[b]{3}{*}{$\begin{array}{l}\text { Phage-typing } \\
\text { patterns }\end{array}$} & \multicolumn{6}{|c|}{ Results of Tween reaction in } \\
\hline & & \multicolumn{3}{|c|}{$\begin{array}{l}\text { egg-yolk positive } \\
\text { strains tested with }\end{array}$} & \multicolumn{3}{|c|}{$\begin{array}{l}\text { egg-yolk negative } \\
\text { strains tested with }\end{array}$} \\
\hline & & $\begin{array}{c}\text { Tween } \\
20\end{array}$ & $\begin{array}{c}\text { Tween } \\
80\end{array}$ & $\begin{array}{l}\text { Tween } \\
85\end{array}$ & $\begin{array}{c}\text { Tween } \\
20\end{array}$ & $\begin{array}{l}\text { Tween } \\
80\end{array}$ & $\begin{array}{c}\text { Tween } \\
85\end{array}$ \\
\hline $\mathbf{I}$ & $\begin{array}{l}52,52 \mathrm{~A}, 80,81 \\
\text { complex }\end{array}$ & $40 / 40^{*}$ & $39 / 39$ & $39 / 39$ & $51 / 57$ & $36 / 57$ & $55 / 57$ \\
\hline $\mathbf{I}$ & Other & $33 / 33$ & $34 / 34$ & $32 / 32$ & $25 / 25$ & $7 / 25$ & $10 / 25$ \\
\hline II & $\cdots$ & $27 / 27$ & $28 / 28$ & $27 / 27$ & $25 / 27$ & $8 / 27$ & $21 / 27$ \\
\hline $\begin{array}{l}\text { III } \\
\text { III }\end{array}$ & $\begin{array}{l}\text { Other } \\
83 \mathrm{~A} \\
84,85,93 \text { complex }\end{array}$ & $\begin{array}{l}30 / 30 \\
30 / 30 \\
30 / 30\end{array}$ & $\begin{array}{l}30 / 30 \\
30 / 30 \\
30 / 30\end{array}$ & $\begin{array}{l}30 / 30 \\
30 / 30 \\
30 / 30\end{array}$ & $\begin{array}{l}30 / 30 \\
31 / 31 \\
52 / 52\end{array}$ & $\begin{array}{l}1 / 30 \\
1 / 31 \\
0 / 52\end{array}$ & $\begin{array}{l}1 / 30 \\
5 / 31 \\
1 / 52\end{array}$ \\
\hline Any & ... & $190 / 190$ & $191 / 191$ & $188 / 188$ & $214 / 222$ & $53 / 222$ & $93 / 222$ \\
\hline
\end{tabular}

* Number of cultures positive/number tested.

\section{RESULTS}

Lipolytic action of Staphylococcus aureus on egg yolk and on Tween compounds Of 413 coagulase-positive staphylococci examined, 191 gave a positive reaction when tested in egg-yolk glucose broth (table II). All egg-yolk positive 
strains gave a positive reaction with Tween 80 and-except for a few that were not tested-also in Tween 20 and Tween 85 .

Among the 222 cultures that gave a negative egg-yolk reaction, 214 (96 per cent.) gave a positive reaction with the short-chain compound Tween 20 , but only 53 (24 per cent.) gave a positive reaction with Tween 80 and 93 (42 per cent.) with Tween 85 . Positive reactions with the longer-chained Tweens were in general more common among egg-yolk negative members of the 52, 52A, 80,81 complex of phage-typing patterns than among other egg-yolk negative

TABLE III

Lipolytic activity of coagulase-negative staphylococci and micrococci from human and animal sources

\begin{tabular}{|c|c|c|c|c|c|c|}
\hline \multirow{4}{*}{$\begin{array}{c}\text { Description of } \\
\text { organisms }\end{array}$} & \multicolumn{6}{|c|}{ Number (and percentage) of organisms from } \\
\hline & \multicolumn{3}{|c|}{ human sources } & \multicolumn{3}{|c|}{ animal sources } \\
\hline & \multirow[b]{2}{*}{ examined } & \multicolumn{2}{|c|}{ with lipolytic action on } & \multirow[b]{2}{*}{ examined } & \multicolumn{2}{|c|}{ with lipolytic action on } \\
\hline & & Tween 80 & Tween 20 & & Tween 80 & Tween 20 \\
\hline $\begin{array}{l}\text { Coagulase-negative } \\
\text { staphylococcci }\end{array}$ & 338 & $237(70)$ & $291(86)$ & 17 & $10(59)$ & $13(76)$ \\
\hline Micrococci & 76 & $12(16)$ & $23(30)$ & 246 & $34(14)$ & $49(20)$ \\
\hline Both & 414 & $249(62)$ & $314(77)$ & 263 & $44(17)$ & $62(24)$ \\
\hline
\end{tabular}

$S$. aureus strains, though most members of phage-group II gave a positive reaction with Tween 85 .

\section{Lipolytic actions and sources of coagulase-negative staphylococci and micrococci}

None of the 677 coagulase-negative strains gave a positive reaction in eggyolk glucose broth; 376 of them (56 per cent.) gave a positive reaction on Tween-20 plates and 293 (43 per cent.) on Tween-80 plates. The coagulasenegative strains of human origin were more strongly lipolytic than were those of animal origin, and classification of the organisms by Baird-Parker's method showed that most of the human strains were staphylococci and most of the animal strains were micrococci (table III). The differences in lipolytic activity of human and animal strains corresponded to the finding that the staphylococci were in general more strongly lipolytic than the micrococci. Baird-Parker $(1963,1965)$ previously reported a similar difference between the lipolytic properties of staphylococci and micrococci. 


\section{Reproducibility and stability of lipolytic actions}

The egg-yolk reaction was previously found to be a stable and reproducible property of coagulase-positive staphylococci (Gillespie and Alder). In the present study, this was also found to be true of the reactions of coagulasepositive and coagulase-negative staphylococci and of micrococci with the Tween compounds. Eighty cultures, of which 12 were coagulase positive and 68 coagulase negative and which included strains that were strongly and weakly lipolytic on Tween compounds, were freeze-dried and tested again 2 yr later, with the same results as before. Four coagulase-positive and four coagulasenegative strains, with lipolytic reactions on the Tween media ranging from very strong to negative, were subcultured successively five times on nutrient agar. Each of the 40 subcultures was then transferred on two consecutive days to nutrient agar plates containing one or other of the three Tween compounds. After incubation at $37^{\circ} \mathrm{C}$ for 3 days, the width of the precipitation zones-if any-was found to be the same as the zones formed by the strains before subculture. It was noted, however, that the precipitation zones on plates seeded from the cultures which had stood for $24 \mathrm{hr}$ on the bench were slightly larger than those on plates seeded from fresh cultures.

\section{Serological differences between lipases active on egg yolk and on Tween compounds, and $\alpha$-toxin}

The nine rabbits inoculated with coagulase-positive staphylococci (table I) became ill, and two died before antibiotic treatment was initiated. Those inoculated with the egg-yolk positive strain became ill more rapidly than did the others and one died. The six rabbits inoculated with coagulase-negative strains remained well.

The pre-injection sera were tested by Ouchterlony's method against extracts of the immunising strains; precipitation lines were not formed. In similar tests, the sera from rabbits immunised with coagulase-positive strains formed numerous heavy lines, whereas those immunised with coagulase-negative strains gave fewer lines, all of which were faint. We do not know whether this difference was due to the stronger antigenic properties of the coagulase-positive strains or to the fact that they caused more prolonged infections in the rabbits and so immunised them more effectively than did the coagulase-negative strains.

The ability of the rabbit sera and of the commercial antiserum to neutralise the actions of the immunising strains in egg-yolk glucose broth and on Tweenagar plates was investigated. Only the sera from rabbits immunised with the egg-yolk positive strain, and the commercial antiserum, neutralised the egg-yolk reaction. None of the sera neutralised the actions of any of the cocci on any Tween compound. Only the sera prepared against the three coagulase-positive strains and the commercial antiserum neutralised staphylococcus $\alpha$-toxin. It was evident, therefore, that $\alpha$-toxin, egg-yolk lipase, and the lipases active on Tween compounds were all antigenically different. 


\section{DisCUSSION}

Our experiments suggest that there are three different kinds of lipase activity among the Micrococcaceae: (1) the reaction in egg-yolk glucose broth, a property shown by some coagulase-positive strains but not by coagulase-negative strains; (2) activity on long-chain fatty-acid compounds such as monooleates and trioleates (Tween 80 and 85 ), a property shared by some coagulase-positive and some coagulase-negative cocci; (3) activity against short-chain fatty-acid compounds, e.g., Tween 20 , and possessed by nearly all coagulase-positive and coagulase-negative cocci. Only the egg-yolk lipase was found to be antigenic in rabbits.

Confusion has arisen from differences in methods of demonstrating the egg-yolk reaction. Gillespie and Alder (1952) found that changes brought about by $S$. aureus on egg-yolk agar were sometimes weak and difficult to read, and were not always neutralised by antiserum. A higher proportion of positive reactions was obtained on egg-yolk agar than in broth, a result also reported by Gare (1969). Spink and Strong (1968), using egg-yolk mannitol agar, obtained positive reactions with some coagulase-negative strains. It is therefore recommended that the term "egg-yolk positive" be confined to strains that produce opacity in egg-yolk glucose broth (Gillespie and Alder) because this reaction is clear cut, fully neutralised by antiserum and never given by coagulase-negative strains.

There clearly are differences between the lipolytic reactions responsible for the egg-yolk test and for the hydrolysis of the various Tween compounds. It may be that the egg-yolk reaction and the Tween reactions are produced by different enzymes, or that a complex of enzymes is responsible, some of which hydrolyse one or more of the Tween compounds in addition to egg-yolk lipid. The stronger reactions with Tween 80 obtained in the present study compared with those of Jessen et al. (1959) may be explained by differences in size of inoculum and duration of incubation. The different serological properties of the " egg-yolk factor" and the enzyme active against Tween 80 might be due to a lack of antigenicity of the latter, or to its being present in too small a quantity to be demonstrated in the method that was employed.

Lacey, Alder and Gillespie (1970) found little difference between the ability of strongly and weakly lipase-producing staphylococci to survive on normal skin. Similar experiments were carried out by one of us (V. G. A.) on covered skin (Lacey 1968), but with a longer period of contact ( $72 \mathrm{hr}$ ) between the organisms and the skin; these also did not reveal much difference between the survival of egg-yolk positive and egg-yolk negative $S$. aureus. Although such experiments do not reproduce natural conditions, there was no suggestion that the preponderance of egg-yolk positive strains in furunculosis, observed by Alder et al. $(1953,1955)$, might be attributable to their greater power of survival on the surface of skin.

Jessen and Bülow (1967) found that Tween 80-positive strains of the 52, $52 \mathrm{~A}, 80,81$ complex, when inoculated into the hair follicles of pig skin, caused boil-like lesions, whereas Tween 80-negative variants (Rosendal and Bülow, 
1965) of them did not do so. The relationship between lipases and virulence of staphylococci should be investigated further.

\section{SUMMARY}

Gram-positive, catalase-positive cocci from man and animals were examined for lipolytic action in egg-yolk glucose broth and on various Tween compounds.

The reaction in egg-yolk glucose broth was given by some coagulase-positive staphylococci but not by any of the coagulase-negative strains. The cultures producing this reaction also attacked all the Tween compounds. In addition, nearly all egg-yolk negative, coagulase-positive staphylococci attacked Tween 20 and a number-particularly members of the 52, 52A, 80, 81 complex of phage-typing patterns-also attacked the longer-chained Tweens. The egg-yolk factor appeared to be antigenically distinct from the lipases that acted on Tween compounds, and from $\alpha$-lysin.

Among the coagulase-negative cocci, the results showed broad differences between human and animal strains. Most of the human strains were staphylococci and were strongly lipolytic, whereas most of the strains from animals were micrococci and were feebly lipolytic.

We wish to thank the Board of Governors of the United Bristol Hospitals for financial support, Dr K. R. Eriksen, Dr N. Mortensen, Dr O. Klaustrup and Dr J. T. Paterson for supplying cultures, Dr H. J. Skovgaard Jensen for supervising the rabbit injections, and Mrs L. Monies and Mrs J. Lockyer for technical assistance.

\section{REFERENCES}

Alder, V. G., Gillespre, W. A., ANd Herdan, G. 1953. Production of opacity in egg-yolk broth by staphylococci from various sources. J. Path. Bact., 66, 205.

Alder, V. G., Gillespie, W. A., AND Thompson, Margaret E. M. 1955. Virulence and phage patterns of antibiotic-resistant staphylococci in hospital. J. Path. Bact., 70, 503.

BAIRD-PARKer, A. C. 1963. A classification of micrococci and staphylococci based on physiological and biochemical tests. J. Gen. Microbiol., 30, 409.

Baird-PARKer, A. C. 1965 . The classification of staphylococci and micrococci from world-wide sources. J. Gen. Microbiol., 38, 363.

Blair, J. E., AND Williams, R. E. O. 1961. Phage typing of staphylococci. Bull. Wld Hlth Org., 24, 771.

BüLow, P. 1968. A new epidemic phage type of Staphylococcus aureus. 3. Occurrence and spread of " type 6557 ", with special reference to the consumption of some antibiotics. Acta path. microbiol. scand., 74, 543.

GARE, Margaret 1969. Egg-yolk reaction of Staphylococcus pyogenes. Pathology, 1, 61.

GillePsie, E. H. 1943. The routine use of the coagulase test for staphylococci. Mon. Bull. Emerg. Publ. Hlth Lab. Serv., $2,19$.

Gillespie, W. A., AND Alder, V. G. 1952. Production of opacity in egg-yolk media by coagulase-positive staphylococci. J. Path. Bact., 64, 187.

Jessen, O., AND BüLOW, P. 1967. Changes of pathogenicity of Staphylococcus aureus by lysogenic conversion influencing lipase production, as evidenced by experimental skin infections in pigs. Acta. path. microbiol. scand., Suppl. 187, 48.

Jessen, O., Faber, V., Rosendal, Kirsten, ANd Eriksen, K. R. 1959. Some properties of Staphylococcusaureus, possibly related to pathogenicity. I. A study of 446 strains from different types of human infection. Acta path. microbiol. scand., 47, 316.

LACEY, R. W. 1968. Antibacterial action of human skin. In vivo effect of acetone, alcohol and soap on behaviour of Staphylococcus aureus. Br. J. Exp. Path., 49, 209. 
LACEy, R. W., Alder, V. G., AND Gillespie, W. A. 1970. The survival of Staphylococcus aureus on human skin. An investigation using mixed cultures. Br. J. Exp. Path., $51,305$.

OUCHTERLONY, O. 1953. Antigen-antibody reaction in gels. IV. Types of reactions in coordinated systems of diffusion. Acta path. microbiol. scand., 32, 231.

Parish, H. J., O'Meara, R. A. Q., and Clark, Winifred, H. M. 1934. The clinical investigation of staphylococcal toxin, toxoid and antitoxin. Lancet, $1,1054$.

Patterson, J. T. 1966. Characteristics of staphylococci and micrococci isolated in a bacon curing factory. J. Appl. Bact., 29, 461.

RAPER, J. R., AND HYATT, Elva A. 1963. Modified press for disruption of microorganisms. J. Bact., 85, 712 .

REPORT 1967. Subcommittee on Phage-typing of Staphylococci, Moscow, July 1966. Int. J. Syst. Bact., 17, 113.

REPORT 1971. Subcommittee on Phage-typing of Staphylococci, Mexico City, August 1970. Int. J. Syst. Bact., 21, 167.

Rosendal, KIRSTEN, AND BÜLOW, P. 1965. Temperate phages influencing lipase production by Staphylococcus aureus. J. Gen. Microbiol., 41, 349.

Scrimgeour, G., Keane, P. M., AND Alder, V. G. 1967. Demonstration of staphylococcal lipase and clostridial lecithinase activity by thin-layer chromatography. J. Path. Bact., 93, 688.

ShaH, D. B., AND Wilson, J. B. 1963. Egg yolk factor of Staphylococcus aureus. 1. Nature of the substrate and enzyme involved in the egg yolk opacity reaction. J. Bact., 85, 516.

SIERRA, G. 1957. A simple method for the detection of lipolytic activity of micro-organisms and some observations on the influence of the contact between cells and fatty substrates. Antonie van Leeuwenhoek, 23, 15.

SpInk, M. S., AND Strong, SHIRLEY 1968. The pathogenic variety of Staphylococcus albus. J. Path. Bact., 95, 295.

Stewart, G. T. 1965. The lipases and pigments of staphylococci. Ann. N.Y. Acad. Sci., $128,132$.

Thomas, MaIR 1961. The sticky film method of detecting skin staphylococci. Mon. Bull. Min. Hlth, 20, 37.

Tirunarayanan, M. O., AND Lundbeck, H. 1968. Investigations on the enzymes and toxins of staphylococci. Relationship of $p \mathrm{H}$ to growth and production of enzymes. Acta path. microbiol. scand., 74, 274. 